\title{
A RESERVA LEGAL NO PARANÁ E OS DESAFIOS À SUA IMPLANTAÇÃO: UM ESTUDO SOBRE OS PRODUTORES RURAIS NO MUNICÍPIO DE PARANACITY-PR*
}

\author{
Alba Regina Azevedo Arana** \\ Gláucia Baldassi***
}

\section{RESUMO}

O presente trabalho procura discutir a Reserva Legal ( $R L)$ no estado do Paraná, apresentando os aspectos que dificultam sua implantação, especialmente junto aos produtores rurais no município de Paranacity. A legislação obriga o produtor rural a recompor e/ou preservar $20 \%$ de suas propriedades como Reserva Florestal Legal. Tal obrigação, de maneira geral, não é bem vista pelos proprietários devido ao fato de que, aparentemente, torna improdutiva uma parcela significativa de suas áreas. O estudo procurou mostrar os diversos argumentos favoráveis e contrários à implantação da RL em $20 \%$ da propriedade rural. A metodologia utilizada recaiu numa pesquisa aplicada junto aos produtores rurais do município. Por meio da pesquisa de campo, verificou-se que os produtores rurais têm consciência da importância da implantação da RL, contudo, temem os impactos imediatos no sistema produtivo.

PALAVRAS-CHAVE: Reserva legal; legislação ambiental; produtores rurais; conservação ambiental; Paranacity.

\begin{abstract}
This work aims to discuss the Legal Reserve $(R L)$ in the state of Parana, presenting the points that hamper its implementation, especially among the rural producers in the municipality of Paranacity. The law requires the producer to revive rural and / or preserve $20 \%$ of its properties as Forest Reserve Legal. This obligation, in general, is not well seen by owners for the fact that, apparently, makes an unproductive significant portion of their areas. The study sought to show the various arguments pro and against the deployment of RL on $20 \%$ of rural property. The methodology used primarily in an applied research with the farmers of the township. Through the search field, it was found that farmers are aware of the importance of implementation of the $R L$, however, fear the immediate impact on production system.
\end{abstract}

KEY-WORDS: Legal reserve; environmental legislation; rural producers; environmental conservation; Paranacity.

\section{Introdução}

Reserva Legal (RL) é a área localizada no interior de uma propriedade ou posse rural, excetuada a de preservação permanente, necessária ao uso sustentável dos recursos naturais, à conservação e reabilitação dos processos ecológicos, à conservação da biodiversidade e ao abrigo e proteção de fauna e flora nativa.
O Código Florestal Brasileiro, Lei no 4.771/ 65, prevê para a Região Sul do país, incluindo aí o Estado do Paraná, que $20 \%$ do total da área das propriedades rurais devem ser averbadas como Reserva Legal e, portanto, não podem ser utilizadas para agricultura ou pecuária.

Desse modo, a questão da Reserva Legal $(R L)$ não é tema novo, pois já era tratado pela

\footnotetext{
${ }^{*}$ Artigo elaborado com base no trabalho de Conclusão do curso de Especialização lato sensu em Gestão Ambiental da Unoeste.

** Geógrafa pela Unesp de Presidente Prudente-SP, Mestre e Doutora em Geografia pela USP, Professora da Graduação e Pós-Graduação da Unoeste. Diretora da Faclepp- Faculdade de Ciências, Letras e Educação da Uoeste de Presidente Prudente. Coordenadora do Curso de Gestão Ambiental da Unoeste. Email: alba@unoeste.br

*** Bióloga pela Unipar - Universidade Paranaense e Pós-Graduação em Gestão Ambiental pela Unoeste. E-mail: glaucia@prcity.com.br
} 
legislação em 1965 e, sob determinados aspectos, bem anterior a isso. Porém, na prática, o Código Florestal não surtiu muito efeito, pois a utilização do solo para agricultura e pecuária na maioria das propriedades do Estado do Paraná, estendese até às margens dos rios, desrespeitando inclusive o espaço da mata ciliar.

Segundo Ehlers (1999), o conhecimento e a habilidade do ser humano não podem substituir as funções desempenhadas pelos ciclos naturais. Porém, esse reconhecimento só acontece quando estes são interrompidos ou perdidos para sempre, como as florestas, cuja importância só foi entendida quando os índices de desmatamento alcançaram níveis críticos para o abastecimento dos recursos hídricos. A conservação da RL na propriedade contribui para - ecossistema por proporcionar abrigo, acasalamento e alimentos para polinizadores e outras espécies silvestres, a proteção do solo contra a erosão e a perda de nutrientes e a manutenção da capacidade de água dos lençóis freáticos, havendo a necessidade de um conhecimento para manejá-la na paisagem rural.

Face a isso, e graças às recentes discussões e modificações na legislação ambiental, que impingiram o caráter de obrigatoriedade, o tema reserva legal voltou a ser pauta de amplo debate e discussão, com os mais diversos argumentos favoráveis e contrários.

A ocupação antrópica no estado do Paraná desencadeou um processo de devastação das florestas clímax que ocupavam aproximadamente $85 \%$ de todo o seu território e que hoje cobrem apenas cerca de 3,4\% do mesmo. Atividades como extração de madeiras, seguida da implantação de lavouras e pastagens, além da expansão urbana, estão entre as responsáveis pela descaracterização da fitofisionomia paranaense. Em decorrência desse desequilíbrio, implantaram-se inúmeros processos prejudiciais ao meio e ao próprio ser humano, como erosão, deslizamentos, assoreamento de cursos d'água, perda de fertilidade do solo, alterações microclimáticas, proliferação de pragas e espécies exóticas, extinção de espécies nativas, entre vários outros, tanto de cunho ambiental quanto social.

No intuito de reverter tais processos, a legislação obriga o produtor rural a recompor e/ ou preservar $20 \%$ de suas propriedades como Reserva Florestal Legal. Essa obrigação, de maneira geral, não é bem vista pelos proprietários devido ao fato de que, aparentemente, torna improdutiva uma parcela significativa de suas áreas. Outro fator que dificulta a recuperação destas é o custo requerido para tal.

É de suma importância a busca de meios para transformar a conservação de fragmentos florestais na forma de Reserva Legal em atividade que traga benefícios diretos e indiretos aos proprietários rurais, tornando-a desejável para estes. Desta forma, este trabalho pretende discutir o tema no Estado do Paraná, mais especificamente no município de Paranacity, enfocando as dificuldades da implantação da reserva legal e verificando os desafios desta implantação junto aos produtores rurais do município.

\section{Caracterização da Área}

Historicamente, a agropecuária sempre desempenhou um papel fundamental na economia paranaense. Nas últimas décadas, a utilização intensiva de novas tecnologias, associadas à melhoria gerencial dos empresários rurais, tem proporcionado incrementos positivos na qualidade dos produtos agropecuários parananeses. De acordo com o IBGE (2002), a estrutura fundiária do estado do Paraná é formada predominantemente por pequenos e médios proprietários; cerca de $86 \%$ dos estabelecimentos rurais apresentam área inferior a 50 hectares.

O município de Paranacity, segundo o IBGE (2002), faz parte da Microrregião de Paranavaí na Região Noroeste do Estado. A Microrregião é composta por 29 municípios e faz divisa a norte com o Estado de São Paulo e a oeste com o Estado do Mato Grosso do Sul (conforme fig. 1). São eles: Alto Paraná, Amaporã, Cruzeiro do Sul, Diamante 
do Norte, Guairaçá, Inajá, Itaúna do Sul, Jardim Olinda, Loanda, Marilena, Mirador, Nova Aliança do Ivaí, Nova Londrina, Paraíso do Norte, Paranacity, Paranapoema, Paranavaí, Planaltina do Paraná, Porto Rico, Querência do Norte, Sta. Cruz de Monte Castelo, Santa Izabel do Ivaí, Santa Mônica, Santo Antônio do Caiuá, São Carlos do Ivaí, São João do Caiuá, São Pedro do Paraná, Tamboara, Terra Rica. (PNUD, 2003).

O clima predominante no município é o subtropical, mesotérmico úmido, com estiagem no inverno, geadas pouco frequentes e tendência à concentração de chuvas nos meses de verão. Os solos são arenosos, planos e ácidos, compondo parte da formação pedológica denominada Arenito
Caiuá, que se caracteriza por baixa fertilidade e baixo teor de matéria orgânica, além de suscetibilidade à deficiência hídrica e erosão.

Nos anos 70, a Microrregião sofreu uma profunda mudança na sua estrutura fundiária em decorrência das geadas. Caracterizada pela pequena propriedade, passou a ser marcada pelos latifúndios. Isso porque as geadas do ano de 1975 provocaram a falência dos pequenos produtores de café da região. Segundo a GAZETA MERCANTIL (ed. 27/04/2005, p. 12) "o frio de $5^{\circ} \mathrm{C}$ graus negativos, seguido de ventos fortes e com baixa umidade, queimou as lavouras de café em área estimada de 1,05 milhões de hectares, apenas no Paraná".

\section{Figura 1- Localização do Município de Paranacity}

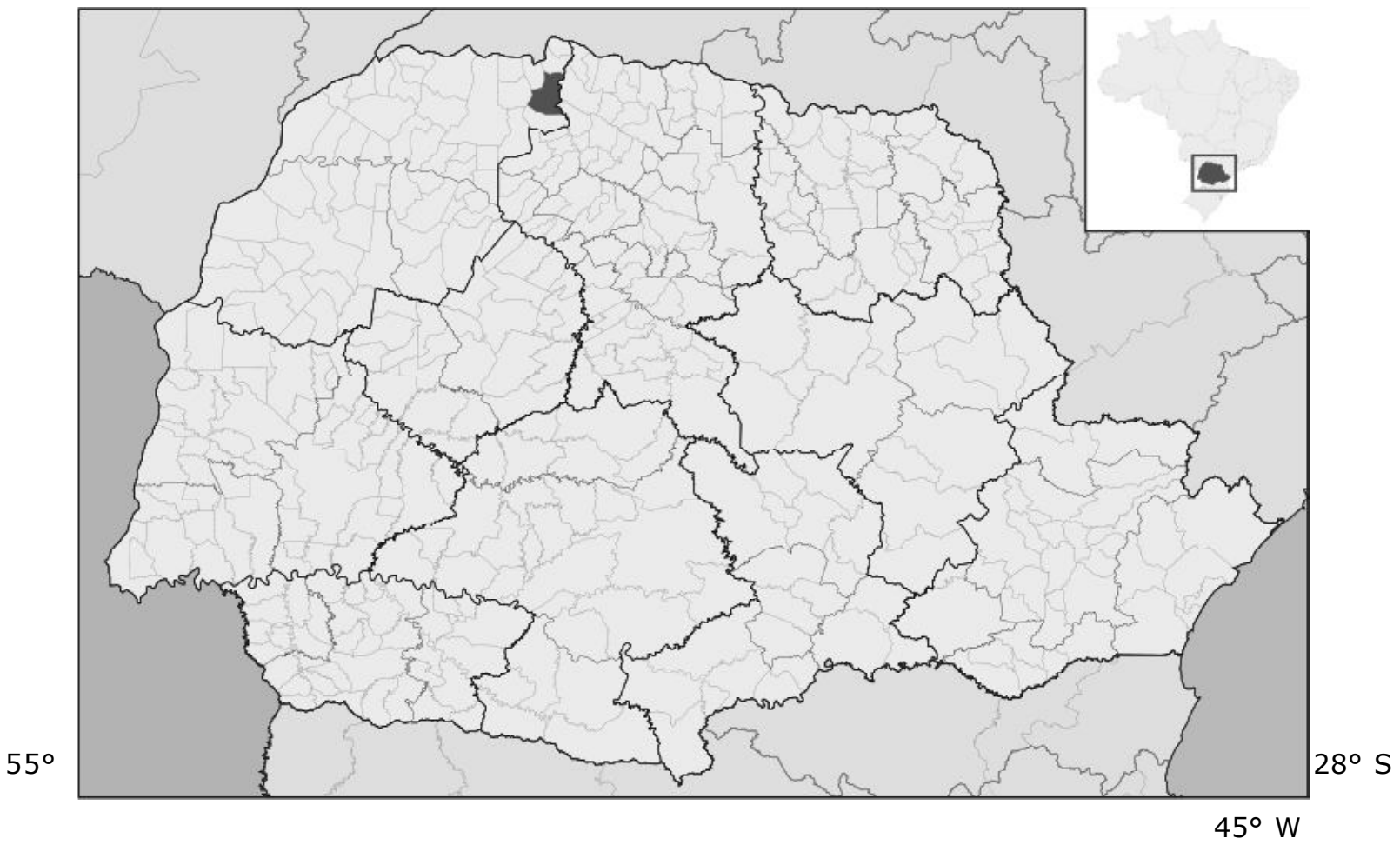

Escala aproximada: 1: 750.000

(coordenadas geográficas do município: latitude $22^{\circ} 56^{\prime} 15^{\prime \prime} \mathrm{S}$ e longitude $52^{\circ} 11^{\prime} 15^{\prime \prime} \mathrm{W}$ )

Fonte: Prefeitura Municipal de Paranacity, 2008. 
Em 1975, a cultura do café foi substituída pela do algodão, o que manteve uma parte dos pequenos produtores. No entanto, a forte queda do preço gerou uma situação insustentável para boa parte deles. "Naquele ano, pelo menos 300 mil cafeeiros, a maioria em pequenas propriedades, foram erradicados e substituídos por algodão e pela seqüência de lavoura de soja e trigo (...)" (idem).

Muitos produtores venderam suas terras para os médios e grandes proprietários que já existiam na região ou vieram de regiões vizinhas. As propriedades foram aglutinadas e destinadas à pecuária de corte extensiva. O solo de Arenito Caiuá estava enfraquecido depois de vários anos de culturas. O município de Paranacity, que chegou a bater o recorde nacional e internacional de café, passou a ser dominado pela criação extensiva de gado. Vale ressaltar ainda outro fato que provocou a concentração fundiária e a transformação no uso do solo: as mudanças na política agrícola ocorridas a partir da segunda metade da década de 1980.

Paranacity também fica próximo de outros importantes centros consumidores, como Maringá e Londrina. Ocupa uma área de 343,8 km2, com uma densidade demográfica de 26,5 (em 2000). A densidade demográfica média da Microrregião é de 22,25 , sendo a maior a de Paranavaí $(62,7)$.

Como se vê no período 1991-2000 a população urbana da Microrregião de Paranavaí

\section{Quadro 1: População urbana e rural da Microrregião de Paranavaí e de Paranacity - 2000}

\begin{tabular}{|l|lc|lc|}
\hline & \multicolumn{2}{|c|}{1991} & \multicolumn{2}{c|}{2000} \\
& ANO & urbana & rural & urbana \\
\hline Mcrorregião Paranavaí & 114.801 & 345.513 & 89.142 & 385.130 \\
\hline Paranacity & 3.441 & 5.087 & 1.783 & 7.326 \\
\hline
\end{tabular}

Fonte: IBGE, censo demográfico, 1991, 2000.

saltou de $75 \%$ para $80,55 \%$. Em Paranacity, no mesmo período, a taxa de urbanização cresceu $22 \%$. Já a rural, tanto em Paranavaí como em Paranacity, diminui significativamente. No último caso a redução foi de $52 \%$.

Do ponto de vista da estrutura fundiária, a Microrregião apresenta porcentagens que indicam uma concentração fundiária paralela à existente em âmbito nacional, apesar dos indicadores do Estado serem mais equilibrados. As propriedades com área superior a 200 hectares acumulam $65,62 \%$ das terras da Microrregião, enquanto no contexto nacional é de $70,73 \%$ e, no Estado do Paraná, é de $49,31 \%$. Portanto, esta Microrregião está mais próxima do valor nacional, conforme dados do Censo Agropecuário (1995-1996), do que do estadual.

A atividade agropecuária de Paranacity está baseada na pecuária e na lavoura permanente e temporária. Em relação à lavoura, o destaque é para cana-de-açúcar, segundo dados do IBGE 2004.

O IBGE destaca quatro produtos na produção animal de Paranacity no ano de 2004: casulos do bicho da seda (kg) 22.927; leite (litros) $1.791 \mathrm{mil}$; mel de abelha (kg) 750; ovos de galinha (dúzias) $430 \mathrm{mil}$ (IBGE - Pesquisa Pecuária Municipal, 2005). 
Em relação à renda, o produto interno bruto (PIB) per capita de 2003, foi de $\mathrm{R} \$ 9.409,00$, segundo dados do IPARDES (2006), sendo a agropecuária a principal atividade.

\section{Quadro 2: Paranacity - Estabelecimentos Agropecuários segundo as atividades econômicas, 2004}

\begin{tabular}{|l|r|}
\hline Atividades Econômicas & Estabelecimento \\
\hline Horticultura & 2 \\
\hline Lavoura permanente & 59 \\
\hline Lavoura tem porária & 58 \\
\hline Pecuária & 274 \\
\hline Produção mista & 35 \\
\hline TOTAL & 428 \\
\hline
\end{tabular}

Fonte: IBGE - Censo Agropecuário, 2004.

Na Microrregião, deu-se a implantação dos assentamentos como resposta à pressão dos movimentos sociais. O primeiro assentamento foi - Santa Maria. Até abril de 2005 foram implantados na Microrregião 28 Assentamentos, numa área de aproximadamente 34 mil hectares para cerca de 1,4 mil famílias.

Um estudo realizado por Gomez (2002) aponta que a Microrregião de Paranavaí tem experimentado mudanças socioeconômicas, políticas e territoriais que extrapolam os números das estatísticas oficiais. Essas mudanças são fruto da organização dos trabalhadores, seja devido ao grande número de famílias assentadas que vem produzindo uma revitalização na economia da sede municipal, perdida com a crise do café, seja em virtude da singularidade da organização - em cooperativas de produção e ou comercialização de assentados de reforma agrária, e das formas de produção desenvolvidas pelos assentados - diversificação produtiva menos intensiva em insumos químicos.

Cabe ressaltar, contudo, que o propósito deste trabalho foi compreender a visão dos produtores rurais quanto à implantação da área destinada à reserva legal em sua propriedade, e buscou-se resgatar os aspectos que dificultam sua implantação.

Segundo dados do IBGE (1990), a área dos estabelecimentos rurais no norte central do Estado, a qual pertence o município de Paranacity, é de $2.221,2$ mil ha, e a área destinada à reserva legal seria de 444,2 mil ha.

De maneira geral, pode-se dizer que a agropecuária paranaense sofrerá um grande impacto econômico sobre seu agronegócio com a implantação da área da reserva legal florestal de $20 \%$. Segundo Padilha Junior e Berger (2005), haverá uma redução de 3,2 milhões de hectares com a implantação da área de reserva no Estado e isto acarretará uma perda anual de $R \$ 3,93$ bilhões ou $19,4 \%$ do total do Valor Bruto da Produção no Estado.

\section{A situação Florestal no Paraná: Aspectos da política estadual.}

O Paraná possuía, até fins do século XIX, uma cobertura vegetal exuberante, onde se destacavam florestas ricas em espécies como o pinheiro, imbuía, perobas, cedros, canelas, ipês, pau marfim e tantas outras de grande importância.

Essas florestas abrigavam uma fauna riquíssima, tanto em quantidade como em variedade de espécies. "Antas, catetos, capivaras, veados, onças, pacas e tantos outros animais e aves eram abundantes e serviam de suporte alimentar a inúmeras gerações dos primitivos habitantes destas terras, os índios. Os rios eram claros, não poluídos e piscosos, não assoreados e raramente transbordavam. Contribuía também para este fato a normalidade do regime das chuvas". (SALAMUNI, 1969, p.23).

A ocupação no Estado desencadeou um processo de devastação das florestas que chegaram a ocupar cerca de $85 \%$ do território e hoje cobrem apenas 3,4\% deste (SEMA, 2003). No início do século $X X$, dois acontecimentos simultâneos contribuíram para o início de uma 
acelerada destruição das matas paranaenses: a descoberta do valor econômico do pinheiro e a implantação da cultura cafeeira. "Ao Sul e ao Norte tem início estes dois ciclos econômicos bastante distintos, mas com base em um ponto em comum, o desperdício" (FUPEF \& SEMA, 2002, p.13).

O quadro atual de cobertura florestal nativa no Paraná revela uma situação alarmante. A região dos planaltos do interior, onde predominavam exuberantes florestas, apresentase hoje muito degradada, constituída de remanescentes pequenos e fragmentados, em diversos estágios de sucessão. A maior perda é verificada nas regiões Oeste e Norte, onde a Floresta Estacional Semidecidual cedeu espaço aos empreendimentos agropecuários. O Centrosul, região da Floresta com Araucária, apresenta ainda um percentual de cobertura florestal um pouco maior, mas com remanescentes bastante alterados, consequência da exploração madeireira. As florestas da região litorânea encontram-se em melhor estado, em especial na Serra do mar onde, pelo acesso difícil, sofreram reduzida pressão antrópica (BLUM E OLIVEIRA, 2005).

Em decorrência destes acontecimentos, houve então a descaracterização da fitofisionomia paranaense. O desequilíbrio se implantou e diversas foram as consequências ao meio ambiente, tais como: erosão, alterações microclimáticas, proliferação de pragas, perda de fertilidade do solo, desertificação, extinção de espécies nativas, entre vários outros impactos ambientais e sociais.

No intuito de reverter este processo, segundo dados do Instituto Ambiental do Paraná - IAP, o Estado do Paraná instituiu, em 1995, uma Política Estadual de Desenvolvimento Florestal com vários mecanismos, objetivando buscar a reposição e/ou preservação florestal no Estado. Com a implantação do Sistema Estadual de Reposição Florestal - SERFLOR, em 1996, o Paraná passou a exigir a reposição florestal.

A iniciativa privada plantou, em média, no período de 1997 a 2000, 24.000 hectares por ano. No mesmo período, implantou-se a descentralização da atividade florestal aos municípios através de um programa denominado de Programa Florestas Municipais, estabelecendo convênios de parceria com 296 municípios do Estado, plantando em média 11.000 ha/ano (INSTITUTO AMBIENTAL DO PARANÁ, 2005).

O estado possui também um programa de produção de mudas em viveiros próprios do Instituto Ambiental do Paraná - IAP, disponibilizando mudas nativas para a recuperação de áreas de Preservação Permanente e Reserva Legal na ordem de 3.000 hectares por ano.

O Paraná foi o primeiro Estado brasileiro a ter o ICMS Ecológico. Na prática significa que no Paraná, entre os critérios utilizados para distribuição dos recursos financeiros do ICMS a que os municípios têm direito constitucionalmente, existe um critério ambiental, conforme descreve o Instituto Ambiental do referido Estado:

Recebem estes recursos, os municípios que possuem unidades de conservação (parques, reservas biológicas, estações biológicas, florestas nacionais, estaduais e municipais, RPPN's, etc.); federal, estadual ou municipal; de domínio público ou privado, ou tenham que preservar mananciais de abastecimento para municípios vizinhos (INSTITUTO AMBIENTAL DO PARANÁ, 2005).

Após a implantação do ICMS Ecológico, houve aumento no número de unidades de conservação no Estado, bem como ocorreram significativas melhorias na qualidade das mesmas, em especial nas unidades de conservação sob a responsabilidade do Estado e dos municípios. Obtiveram-se também melhorias da água de grande parte dos mananciais de abastecimento público contemplado pela lei. Além das unidades de conservação, o ICMS Ecológico apoia as populações indígenas, atua fomentando a participação do setor privado na conservação da biodiversidade e as comunidades dos faxinais, existentes na região Centro-sul do 
Paraná que vivem sob um modelo de produção comum, há mais de um século.

A meta do Estado do Paraná é beneficiar todos os municípios do Estado. Para tanto, o projeto não funciona de forma isolada, mas de maneira articulada com outros projetos da Secretaria do Meio Ambiente - SEMA e outros órgãos do Estado.

É de extrema importância a busca de meios para transformar a conservação de fragmentos florestais na forma de Reserva Legal trazendo benefícios indiretos e diretos aos proprietários rurais, tornando desejável para estes. Desta forma, é imprescindível conhecer a legislação para o processo de conservação e ampliação dos remanescentes florestais no Paraná.

\section{A legislação e a Reserva Legal.}

Desde os primórdios da colonização no Brasil, por razões econômicas e não ambientais, já havia uma certa preocupação com a utilização das florestas, especialmente certas madeiras especiais, conforme descreve Joels:

A preocupação em preservar parte das matas das propriedades rurais é bem antiga em nosso país. Já estava presente na época do Brasil Colônia, quando a escassez de madeira adequada, para a construção das embarcações da frota portuguesa, levou a Coroa a expedir as cartas régias, que declaravam de sua propriedade toda a madeira naval, denominada como "madeira de lei" nome ainda utilizado para designar as madeiras nobres em nosso país. (JOELS, 2002 p. 02).

Entretanto, o arcabouço da legislação, segundo a concepção moderna e atualmente conhecida, passou a ser montado muito tempo depois:

[...] a iniciativa de criação de um Código Florestal só surgiu por volta de 1920, quando o presidente Epitácio Pessoa formou uma subcomissão para elaborar o anteprojeto do futuro Código Florestal. Em 1934, por fim, o projeto foi transformado no Decreto no 23.793, que com o passar do tempo ficou conhecido como o Código Florestal de 34. Dentre as inúmeras inovações que este Código trouxe, a mais ousada foi a que criou o limite do direito de uso da propriedade, a chamada "quarta parte", ou seja, a reserva obrigatória de vinte e cinco por cento de vegetação nativa de cada propriedade rural. Desde o início, essa medida foi considerada pelos fazendeiros e madeireiros um sacrifício ao direito de propriedade e uma restrição grave ao uso economicamente viável do imóvel rural. (JOELS, 2002, p. 03).

Anteriormente a isso, a Constituição Imperial de 1824, que garantia o direito à propriedade, em seu art. 179, inc. XXII, já impunha restrições à mesma em favor do bem público.

XXII. É garantido o Direito de Propriedade em toda a sua plenitude. Se o bem público legalmente verificado exigir o uso, e emprego da Propriedade do Cidadão, será ele previamente indenizado do valor dela. A lei marcará os casos, em que terá que jogar esta única exceção, e dará as regras para se determinar a indenização. (CONSTITUIÇÃO IMPERIAL)

Esta mesma matéria foi tratada posteriormente pela Constituição Republicana de 1891 e pela de 1934 que, em seu art. 113, inc. 17, manteve o direito de propriedade, mas explicitou que não poderia ser exercido contra o direito social ou coletivo.

As Cartas posteriores, de 1937, 1946, 1967 e a Emenda Constitucional de 1969, considerada por alguns como uma nova constituição, mantiveram o direito de propriedade, porém sem fazer restrição à mesma ou referência à sua função social. Situação esta que retornou em pauta e com maior força em 1988, quando da nova Constituição democrática.

Instituído pela Lei Federal no 4.771/65, de 15/09/1965, o Código Florestal, que na época foi chamado de novo, já denotava sua preocupação com a questão da preservação 
ambiental para o bem da sociedade como um todo, estando assim expresso em seu primeiro artigo:

\begin{abstract}
Art. $1^{\circ}$ As florestas existentes no território nacional e as demais formas de vegetação, reconhecidas de utilidade às terras que revestem, são bens de interesse comum a todos os habitantes do País, exercendo-se os direitos de propriedade, com as limitações que a legislação em geral e especialmente esta Lei estabelecerem.

Parágrafo único. As ações ou omissões contrárias às disposições deste Código na utilização das florestas são consideradas uso nocivo da propriedade. (CÓDIGO FLORESTAL, 1965).
\end{abstract}

Pela profundidade deste primeiro artigo do Código Florestal Brasileiro e suas consequências implícitas, o legislador, quando da elaboração da Constituição Federal, em 1988, tomou o cuidado de restringir o uso da propriedade, estabelecendo respeito à função social da mesma (art. 50, XXII, CF) e estabeleceu posteriormente (art. 186, CF), critérios e graus de exigência:

Art. 186. A função social é cumprida quando
a propriedade rural atender, simultaneamente, segundo critérios e graus de exigência estabelecidos em lei, aos seguintes requisitos:

I - Aproveitamento racional e adequado;

II - Utilização adequado dos recursos naturais disponíveis e preservação do meio ambiente; III - Observância das disposições que regulam as relações de trabalho;

IV - Exploração que favoreça o bem-estar dos proprietários e dos trabalhadores. (CONSTITUIÇÃO FEDERAL, 1988).

O Código Florestal de 1965, no seu art. 20 , considerou de preservação permanente as florestas e demais formas de vegetação situadas em locais essenciais à manutenção de um meio ambiente sadio. Por exemplo, a alínea a) trata das matas ciliares, essenciais para a qualidade das águas dos rios; a alínea e) cuida das encostas dos morros, ou parte delas, com declividade superior a 45 graus, equivalente a $100 \%$ na linha de maior declive, com o nítido escopo de evitar que em época de chuvas fortes sejam destruídas construções ou que se achar no local (FREITAS, 2000, p. 138-139).

Contudo, o vocábulo Reserva Legal - RL passou a ser amplamente difundido somente anos mais tarde, conforme explica Joels:

A denominação de reserva legal veio a partir da Lei 7.803, de 18 de julho de 1989, que introduziu, também, a exigência de averbação ou registro da reserva legal à margem da inscrição da matrícula do imóvel, sendo vedada a alteração de sua destinação, nos casos de transmissão, a qualquer título, ou desmembramento da área (Art. $16 \& 2^{\circ}$ ). (JOELS, 2002, p. 02-03).

Devido ao surgimento de novas tecnologias, ao avanço das fronteiras agrícolas, à necessidade de adequação e à inserção da cultura preservacionista, a Lei no 4.771/65 Código Florestal sofreu algumas alterações significativas do ponto de vista econômico e ambiental.

Segundo Moraes (2000, p. 103), as mais recentes modificações do Código Florestal ocorreram em maio de 2000 e foram acompanhadas por vários segmentos da sociedade civil mobilizada, organizações não governamentais ambientalistas e entidades representantes dos agricultores, alcançando ampla repercussão na mídia de todo o país.

Em relação à reserva legal, contesta-se o limite do direito de uso da propriedade e os percentuais de $20 \%, 35 \%$ e $80 \%$ de área do imóvel destinada à reserva legal, de acordo com a região e a fisionomia vegetal (MP no. 195650/00, Art. 16, inciso II).

Nesse sentido, Joels (2002, p. 3) lembra da mobilização da sociedade civil organizada e do próprio Ministério Público a respeito do caso:

o movimento contou com a participação intensa do Ministério Público de vários estados. Os procuradores do Estado de São 
Paulo, em um manifesto em defesa do Código Florestal de 1965, consideraram que o debate que antecedeu as suas últimas alterações deu-se em torno de duas propostas levadas à discussão na Comissão Mista do Congresso. Uma delas, a do Deputado Moacyr Micheletto (PMDB-PR), parlamentar ruralista, representante da Confederação Nacional da Agricultura CNA, flexibilizava as exigências da reserva legal e atendia aos anseios do setor produtivo rural. E outra, do Conselho Nacional do Meio Ambiente - CONAMA, que reuniu e consolidou propostas de várias entidades públicas e civis de todo o país, inclusive a de representantes do segmento rural. Diante das manifestações negativas da sociedade ao projeto do Deputado Moacyr Micheletto, o Presidente Fernando Henrique Cardoso foi levado a editar, em 27 de maio de 2000, a Medida Provisória no. 1956-50, que incorporou, no geral, a proposta do CONAMA" (JOELS, 2002, p. 3).

Foram muitas as discussões a respeito da RL e, dentre os pontos contemplados na Medida Provisória no. 1956-50/00, destacase o chamado mecanismo de compensação da reserva legal, o qual oferece ao produtor rural que não dispõe dessa área em sua propriedade a alternativa de compensá-la em outra região, equivalente em extensão e relevância ecológica, na mesma microbacia hidrográfica (Art. 44, inciso II). Outro destaque dessa MP é a definição, pela primeira vez, da função da reserva legal como área de conservação da biodiversidade, retirando o caráter utilitarista que acompanhou a reserva legal desde os primórdios de sua criação, sendo assim definida como: "área localizada no interior de uma propriedade ou posse rural, excetuada a de preservação permanente, necessária ao uso sustentável dos recursos naturais, à conservação e reabilitação dos processos ecológicos, à conservação da biodiversidade e ao abrigo e proteção de fauna e flora nativa" (JOELS, 2002, p. 03).
A exigência da prática da reserva legal florestal nas propriedades rurais brasileiras, instituída pela Lei Federal n.0 7.803/89 e alterada pela Medida Provisória n.0 2. 166$67 / 01$, que modificou a Lei Federal n.0 4.771/ 65 (Novo Código Florestal), estabelece que todo produtor fica obrigado a preservar $20 \%$ da área de sua propriedade, quando situada na Região Sul do Brasil. Além disso, precisa registrar essa disposição à margem da matrícula no cartório de registros de imóveis da comarca, caso contrário, ficará sujeito às sanções previstas na respectiva lei.

Sendo assim, além de todos os problemas técnicos e econômicos inerentes à atividade de produção, os produtores rurais do Paraná estão agora sujeitos à cobrança, pelo órgão ambiental, da implementação da reserva legal florestal e da recomposição da preservação permanente nas suas propriedades.

De acordo com informações verbais obtidas no IAP, até o final de 2002 foram averbadas cerca de 20.000 Reservas Legais no Estado, representando cerca de $5,4 \%$ do total de propriedades rurais paranaenses e englobando em torno de $5,0 \%$ da área total do Estado. Tais averbações ocorrem principalmente em grandes propriedades agrícolas ou de silvicultura industrial, cujas áreas de Reserva Florestal Legal representam maior extensão. No caso das pequenas e médias propriedades, a situação mostra-se distinta.

Os pequenos e médios proprietários, encarando a Reserva Florestal Legal como "imobilização econômica" de parte de suas propriedades e aproveitando a falta de condições de fiscalização em que se encontram os órgão ambientais, acabam evitando a averbação da Reserva Legal por entenderem que esta área seria perdida em termos de produtividade rural. A falta de informação e de assessoria técnica por parte dos órgãos ambientais e de extensão rural aos produtores contribuem para a estagnação do processo. 


\section{Material e Método}

A pesquisa abrangeu a área o Município Paranacity no estado do Paraná, enfocando as dificuldades da implantação da reserva legal e tratando dos desafios desta implantação junto aos produtores rurais do município.

Operacionalmente, a pesquisa passou por três etapas metodológicas: uma primeira etapa na qual se realizou a revisão bibliográfica sobre o assunto em livros, artigos e revistas especializadas. Um segundo momento, em que foi realizado o levantamento de dados e informações secundárias sobre o tema em órgãos e entidades.

Em um terceiro momento, foi realizado um trabalho de campo junto aos produtores rurais do município de Paranacity-PR. A pesquisa foi realizada nos meses de setembro e outubro de 2005; a coleta de dados se deu através de depoimentos (relatos orais), com o uso de gravador. Foram entrevistados cerca de 24 produtores rurais, assim distribuídos: 08 produtores no assentamento Santa Maria; 08 em Inajá e 08 em Jardim Olinda (assentamento Mãe de Deus), o objetivo era obter uma amostra qualitativa dos dados.

A área do assentamento Santa Maria é proveniente de uma antiga fazenda de 256,52 hectares que foi desapropriada pelo decreto número 96.259 , de 30 de junho de 1988 , por ser considerada improdutiva. Desse total, 32 hectares é espaço de preservação ambiental com vegetação de floresta tropical perenifólia, apresentando as seguintes espécies: peroba, pau d'alho, canela, guajuvira, figueira branca, dentre outras. A área do imóvel limita-se com a zona urbana de Paranacity e fica às margens da rodovia PR-164 (faz ligação entre Paranacity e Inajá), é cortada pelo córrego Inhaúmas, que possui duas nascentes permanentes as suas margens. O relevo predominante classificase como suave ondulado $(83,24 \%)$ e ondulado $(16,76 \%)$.
Cabe ressaltar o porquê da escolha de alguns assentamentos para a obtenção da coleta de dados junto a produtores rurais do município de Paranacity-PR: houve a preocupação de optar por assentamentos já implantados e que estivessem numa fase madura do ponto de vista de produção. O universo empírico escolhido, portanto, procurou selecionar produtores com trajetórias de vida diferentes e que poderiam fornecer elementos para entender a complexidade da visão sobre a importância da implantação da reserva legal.

Durante a etapa de obtenção dos dados, foi realizada uma primeira visita ao local e este contato inicial serviu para colher as primeiras impressões, possibilitando um clima de confiança e de tranquilidade que permitisse ao entrevistado relatar sua opinião.

Os depoimentos orais foram transcritos com base nas orientações metodológicas de Queiroz (2004). A fim de garantir a qualidade e riqueza das informações obtidas nos relatos, as entrevistas foram planejadas e orientadas por um roteiro de questões.

A pesquisa utilizou a abordagem qualitativa, definida aqui como aquela que privilegia a análise de microprocessos, através do estudo das ações sociais individuais e grupais, realizando um exame intensivo dos dados, e caracterizada pela heterodoxia no momento da análise. A investigação quantitativa atua em níveis de realidade na qual os dados se apresentam aos sentidos e têm com campo de práticas e objetivos trazer à luz fenômenos, indicadores e tendências observáveis. A investigação qualitativa trabalha com valores, crenças, hábitos, atitudes, representações, opiniões e adequa-se a aprofundar a complexidade de fatos e processos particulares e específicos a indivíduos e grupos.

Com base nas informações obtidas, apresentadas resumidamente a seguir como resultados, foi possível verificar as dificuldades da implantação da área da reserva legal florestal no Estado. 


\section{Resultado e Discussão}

Por meio da pesquisa de campo, verificou-se que os produtores rurais têm consciência da importância da implantação da $R L$, contudo, temem os impactos imediatos no sistema produtivo. No item que se refere ao conhecimento sobre a reserva legal - RL e a obrigatoriedade legal da implantação, 100\% (24) dos produtores responderam afirmativamente que têm conhecimento sobre o assunto e entendem a importância da preservação ambiental no campo. Isso demonstra, portanto, que conhecem a existência da legislação e possuem um certo grau de consciência ambiental.

No que se refere ao percentual de $20 \%$ da Reserva Legal, cerca de $83 \%$ dos entrevistados acham que este percentual é muito grande e $16 \%$ responderam ser ideal. Mostra-se assim, que a grande maioria dos produtores rurais são contrários à área da RL da forma como está colocada.

Quando perguntados se a área de mata ciliar deveria ser considerada para a composição da $\mathrm{RL}, 75 \%$ dos produtores responderam que sim. Essa resposta demonstra que o tema não é uma questão acabada e que as discussões em torno do assunto, no futuro, poderão provocar modificações na legislação ambiental.

No quesito sobre ser ou não favorável à $R L$, do total dos entrevistados (24), 16 produtores rurais respondem sim, ou seja, $66 \%$ concordam com a RL, mas não concordam com o tamanho da mesma, ou seja, acham que deveria ser menor. Isso leva a crer que, se o percentual para recomposição da RL fosse menor, talvez se obtivesse uma maior adesão inicial dos produtores agrícolas para sua recomposição, sem a necessidade de aplicação das sanções legais.

Quando perguntados se acreditavam que a legislação sobre a RL iria ser mudada, face às discussões que estão acontecendo, 58\% (15 produtores) disseram que não e apenas $42 \%$ (10 produtores) estão esperançosos de que isso aconteça. Portanto, a pressão dos produtores agrícolas no Estado do Paraná sobre parlamentares e entidades representativas ainda é muito grande para que se modifique a lei.

Segundo ainda, dados obtidos em trabalho de campo, verificou-se que nas propriedades entrevistadas, a área coberta de RL está em cerca de $21,44 \%$, atendendo os $20 \%$ exigidos por Lei e havendo ainda um excedente de $1,44 \%$ ou 31,0826 ha. Porém, essa distribuição não é uniforme, pois enquanto em algumas propriedades existem grandes áreas de RL para ceder outras necessitam da restauração de toda a área proposta.

Seria interessante destacar, ainda, que existem 11 propriedades (cerca de $46 \%$ do total de 24 propriedades) que não possuem nenhuma área de $\mathrm{RL}, 13$ propriedades (cerca de $54 \%$ ) que possuem uma área de $\mathrm{RL}$ atendendo até $24 \%$ dos $20 \%$ da área total da propriedade exigido pela Legislação. Dos produtores rurais entrevistados verificou-se ainda que, do total 24, 13 produtores que possuem áreas de RL, apenas 7 (cerca de $29 \%$ ) produtores possuem áreas que correspondem de 25 a $49 \%$ do exigido, 4 propriedades (16\%) com áreas de $\mathrm{RL}$ representando mais de $50 \%$ do exigido e 2 ( $8 \%$ ) propriedades que possuem áreas de $\mathrm{RL}$ atendendo $75 \%$ ou mais.

Desta forma, é de suma importância a busca de meios para transformar a conservação de fragmentos florestais na forma de Reserva Legal em atividade que traga benefícios diretos e indiretos aos proprietários rurais, tornando-a desejável para os produtores rurais.

\section{Considerações Finais}

O tema Reserva Legal não é assunto acabado. Muitas discussões já ocorreram e estão acontecendo em diversos níveis, sociedade civil organizada, produtores rurais, entidades não governamentais de proteção ambiental ou poder público constituído (Congresso Nacional e governo). 
Sob o ponto de vista dos produtores rurais, demonstrado pela pesquisa de campo, a maioria das pessoas envolvidas nas lides rurais, responsáveis pela recomposição da reserva legal, são favoráveis a ela, mas querem que a legislação seja flexibilizada no intuito de diminuir o impacto econômico que ela irá gerar, especialmente ao pequeno produtor.

Por outro lado, os defensores da manutenção da RL e seu percentual (segundo entrevista realizada) querem maior rigor na fiscalização, inclusive com aplicação de multas. Isso é o que vem acontecendo no Estado do Paraná, onde o Ministério Público tem agido com severidade no sentido de fazer cumprir a lei e já tem aplicado duras penas àqueles que não respeitam os limites da mata ciliar e promete fazer o mesmo, futuramente, com a reserva legal.

É importante salientar que a implantação e/ou manutenção da Reserva Florestal Legal é vital para a conservação ambiental e obrigatória por lei. Contudo, um dos maiores empecilhos à consolidação do manejo sustentável de Reservas Florestais Legais no Estado são os entraves impostos pela legislação ambiental e pelo órgão ambiental que, por motivos como falta de contingente e equipamento para efetuar fiscalização, acabam por não permitir a exploração sustentável de recursos florestais nativos para não aumentarem seu volume de trabalho.

É de suma importância o aprofundamento de pesquisas a respeito dos entraves da conservação ambiental, de maneira a subsidiar planos de manejo sustentável consistentes e que garantam a conservação destas. O produtor rural também deve, para estabelecer um sistema de manejo sustentável da Reserva Legal, conhecer os recursos florestais existentes em sua região, através de inventário da comunidade vegetal, de maneira a subsidiar futuras ações de manejo. Salienta-se ser de vital importância a agregação de valor aos produtos oriundos da exploração sustentável da Reserva Florestal Legal para que esta atividade alcance os melhores retornos econômicos possíveis, viabilizando a manutenção destes sistemas racionais de produção.

Conclui-se que é necessária uma reavaliação do conceito de Reserva Florestal Legal no sentido de viabilizá-la ecológica e economicamente, dentro de um processo de auxílio mútuo no qual todas as partes obtém benefícios.

\section{Referências Bibliográficas}

BLUM, C.e OLIVEIRA, R. Reserva florestal Legal no Paraná, alternativas de recuperação e utilização sustentável, 2005. www.biodiversidade.rs.gov.br/arquivos

CONSTITUIÇÃO DA REPÚBLICA FEDERATIVA DO BRASIL DE 1988.www.planalto.gov.br

CONSTITUIÇÃO POLÍTICA DO IMPÉRIO DO BRASIL (de 25 de março de 1824). Www.planalto.gov.br

EHLERS, E., Agricultura sustentável: origens e perspectivas de um novo paradigma. 2 . ed. Guaíba: Agropecuária, 1999. Resumos do V CBA - Uso e Conservação de Recursos Naturais Rev. Bras. de Agroecologia/out. 2007 Vol.2 No.2.
FREITAS, V.P. A constituição federal e a efetividade das normas ambientais. São Paulo: Revista dos Tribunais, 2000. 246 p.

QUEIROZ, Suely Robles Reis de. Espaço público e privado em depoimentos orais. In: Teresa M. Malatian; Marisa Saenz Leme; Ivam A Manoel. (Org.). As múltiplas dimensões da política e da narrativa. São Paulo: UNESP/OIho d'Água, 2004.

GAZETA MERCANTIL. Lavouras do PR foram devastadas há 30. Disponível em: www.gazeta mercantil.com.br, acesso: em abril de 2005.

GÓMEZ, J.R.M. Políticas públicas de desenvolvimento rural e o projeto de reforma agrária do MST no Noroeste do Paraná: Uma contribuição ao entendimento do conflito 
capital $x$ trabalho, da gestão territorial do Estado e do controle social do capital. Dissertação (Mestrado em geografia) - Centro de Ciências Humanas, Letras e Artes, Universidade Estadual de Maringá, Maringá, 2002.

GOVERNO do ESTADO do PARANÁ. Disponível em: www.parana.gov.br, acesso maio/2005.

IPARDES. Cadernos Estatísticos: Município de Paranacity. Disponível em www.ipardes.gov.br, acesso em abril de 2006.

JOELS, L.M. Reserva legal e gestão ambiental da propriedade rural: um estudo comparativo de agricultores orgânicos e convencionais do Distrito Federal. 2002. Disponível em: <www.planetaorgânico.com.br>. Acessado em 12 ago. 2005.

IBGE - INSTITUTO BRASILEIRO DE ESTATÍSTICA E GEOGRAFIA. Censo agropecuário 1995 e 2000.Disponível em: www.ibge.gov.br, acesso em março/2005.

IBGE. Censo Agropecuário 1995-1996. Disponível em:<http://www.ibge.gov.br/>. Acesso em: 14 mar. 2007.

INSTITUTO AMBIENTAL DO PARANÁ, Governo do Estado - Legislação Ambiental, 2005.Disponível em: < www.pr.gov.br/meioambiente/iap >. Acesso em: 18 jul. 2005.

MORAES, L.C.S. Código florestal comentado. 2. ed. Atlas, São Paulo: 2000. 272p.

PADILHA JUNIOR, João Batista e BERGER, Ricardo. O impacto da Reserva Legal Florestal sobre a agropecuária paranaense, em um ambiente de risco. Revista FAE, Curitiba. v.8, n.1. p.51-68, jan/jun.2005.

PNUD. Atlas do Desenvolvimento Humano do Brasil. Brasília, 2002.

RIBEIRO, J. A. Campanha de valorização das reservas legais e matas ciliares. 2. ed. Ministério do Meio Ambiente. Porto Velho: 2001. 41 p.

SALAMUNI, R. História do Paraná. Vol. 3, Grafipar.Curitiba: 1969, 107 p.

SEMA. Secretaria Estadual do Meio Ambiente e Recursos Hídricos do Paraná. Atlas da Vegetação do Estado do Paraná - 2002. Disponível em: <http://www.pr.gov.br/sema/atlas.shtml>. Acesso em: 20 mai. 2003.

FUPEF \& SEMA. Mapeamento dos Remanescentes da Floresta Estacional Semidecidual. Curitiba: FUPEF - SEMA, 2002. 69 p. Relatório técnico.
Trabalho enviado em Agosto de 2008

Trabalho aceito em Setembro de 2009 
